\title{
Cuando todo falla. Anatomía de la Gran Depresión, 1929-1939
}

\author{
Luis M. ${ }^{\text {a }}$ Bilbao \\ Dpto. de Análisis Económico: Teoría Económica e Historia Económica \\ Universidad Autónoma de Madrid \\ Ramón Lanza \\ Dpto. de Análisis Económico: Teoría Económica e Historia Económica \\ Universidad Autónoma de Madrid
}

\section{INTRODUCCIÓN}

La virulencia de la actual crisis financiera y sus efectos sobre el crecimiento están avivando la memoria de trances históricos similares, muy en especial la crisis de 1929 y la depresión de los años 30, e incitando a escrutar aquel turbulento pasado con el propósito de extraer de él eventuales lecciones con las que prevenir futuras situaciones de fragilidad financiera. Economistas e historiadores se han entregado a poner luz en la presente crisis desde una perspectiva histórica, recuperando el interés por la literatura sobre historia de las crisis financieras en general y la del 29 más en particular. En este contexto historiográfico y como pórtico a las colaboraciones de este número de la revista, el presente trabajo pretende hacer memoria de aquella crisis, la más grave de cuantas hasta ahora se conocen, y la depresión a que dio lugar, poniendo al descubierto los procesos por los que los «felices años 20» derivaron en los «catastróficos 30», diseccionando para ello la anatomía de la crisis y la depresión.

La literatura que sobre ellas se ha producido es tan copiosa como controvertida. Es uno de los temas historiográficos sobre los que más se ha investigado y del que se han dado algunas «interpretaciones magnas», ya clásicas, pero tan dispares y hasta competitivas que el debate permanece abierto. El tema ostenta tantas facetas, con relaciones tan complejas e intrincadas, que sigue siendo un puzzle de difícil solución. 
Pero aunque no se haya conformado aún un consenso general, en los últimos años sí ha mejorado la comprensión de la macroeconomía de los años 30 y han apuntado acuerdos sobre cuestiones fundamentales. Y como quiera que no hay un factor que por sí solo explique satisfactoriamente la rápida y severa contracción económica de aquellos años, hemos optado, siguiendo el enfoque de Eichengreen (1992b: 224), por una aproximación ecléctica al tema, más propia de la perspectiva histórica, que consiste en seguir la sucesión ordenada de los hechos históricos y diseccionarlos para descubrir su anatomía, léase, las relaciones causales existentes entre los mismos y con las decisiones de política económica que se tomaron para afrontarlos, tanto fuesen para bien como para mal.

La exposición seguirá un orden cronológico que parte, previamente, de una sintética recapitulación de las dimensiones de la depresión desde una perspectiva macroeconómica. Después se abordarán los principales cambios estructurales experimentados en las décadas precedentes, por cuanto no cabe duda que los orígenes de la depresión se encuentran en buena medida en las perturbaciones provocadas por la Gran Guerra, los acuerdos de paz y la reconstrucción del sistema monetario internacional. A continuación se expondrá el tránsito de la crisis a la depresión, siguiendo el curso de la recesión que surge a raíz del doble giro de la política monetaria de la Reserva Federal en 1927-1928, prosigue con la crisis bursátil, se agrava debido a la espiral deflacionista y termina con la salida de Estados Unidos del patrón oro en 1933. A este apartado central del trabajo seguirá un último epígrafe en el que se plantea cuáles fueron las bases de la recuperación económica, que no pudo ser fácil ni perdurable debido a la ruptura de la economía internacional.

\section{LAS DIMENSIONES DE LA DEPRESIÓN}

La Gran Depresión fue calificada por J. M. Keynes en 1931 como «la mayor catástrofe económica de los tiempos modernos» (Fearon, 1978: 9). Su cronología y coyuntura general deben ser recordadas. Los primeros síntomas de la depresión se dejaron sentir desde el otoño de 1928 en los países exportadores de bienes primarios y los países deudores como Alemania, aunque el origen se situaba en los Estados Unidos. En este país, la recesión comienza en junio de 1929 según los ciclos del National Bureau of Economic Researches. El cambio de tendencia de la fase alcista del ciclo en los años 20 es, por tanto, anterior e independiente de la crisis bursátil del 29. Pero lo que parecía en principio un acontecimiento similar a otras recesiones del pasado acabará profundizándose y prolongándose por causas diversas, que se sucederán con ocasión del crash de la 
bolsa de valores en 1929 y la crisis financiera de 1931, hasta tocar fondo entre el otoño de 1932 y la primavera de 1933. Esta cronología genérica tuvo sus particularidades nacionales, especialmente en la fase de recuperación. Ésta comenzó en 1932 o 1933 y por lo común fue tan lenta, agonizante y difícil que no culminó sino varios años más tarde, unos tres como mínimo, y en algunos países como Estados Unidos no se lograría sino en plena Guerra Mundial. La duración de la depresión no deja de ser una primera medida de sus proporciones.

El comportamiento de las principales variables macroeconómicas, reflejado en las Tablas 1 y 2 , evidencia las dimensiones de la depresión. De forma general y agregada, cantidades, tanto producidas como intercambiadas, y precios se deslizaron fuertemente a la baja, al igual que el empleo y a diferencia de los salarios reales, que subieron; contracción, deflación y ocupación fueron de la mano, replicando el patrón clásico de las crisis y recesiones del siglo XIX. Sectorialmente, la producción de alimentos se mantuvo relativamente estabilizada, mientras la industrial resultó la más afectada, seguida de cerca por la de las materias primas y el volumen del comercio. La depresión fue, por tanto, esencialmente industrial pero también comercial, pues los intercambios internacionales persistieron deprimidos en tanto las producciones recuperaron los niveles de 1929. Geográficamente, la severidad y persistencia de la depresión fueron mayores en Estados Unidos que en Europa y el resto del mundo. La producción agregada cayó más en Norteamérica (28\%) que en Europa (11\%) y la recuperación se dilató allí más que aquí. Pero también los países productores y exportadores de productos primarios fueron víctimas destacados de la depresión ${ }^{1}$.

$\mathrm{Ni}$ todas las industrias ni todos los países industrializados se vieron igualmente involucrados en la depresión. Sintomáticamente, las industrias de bienes duraderos, como automóviles y electrodomésticos, y de capital sufrieron más que las de consumo (James, 2001: 136). Pero la consecuencia, esperable, de que cuanto mayor fuese el nivel industrial de un país mayor sería la caída del sector se cumple en el caso de Estados Unidos (-46\%) en relación al conjunto de Europa (-28\%), pero no en el interior de ésta. Entre las naciones muy industrializadas, Alemania y Bélgica experimentaron serias pérdidas en su producción industrial, pero no el Reino Unido ni Francia. Y entre las menos industrializadas, Austria o Polonia sufrieron serios reveses, no así España.

${ }^{1}$ En 15 países de América Latina (representaban el 92\% del PIB de la región en 1950) el PIB y el PIB p/c cayeron respectivamente un 15 y $20 \%$ entre 1929 y 1932, más por tanto que en Europa (Maddison, 2003). 
Tabla 1. Producción, precios y comercio mundiales, 1929-1937 (Números índices, 1929=100)

\begin{tabular}{|c|c|c|c|c|c|c|c|c|c|}
\hline & 1929 & 1930 & 1931 & 1932 & 1933 & 1934 & 1935 & 1936 & 1937 \\
\hline \multicolumn{10}{|l|}{ Producto Interior Bruto * } \\
\hline Mundo & 100 & $\ldots$ & $\ldots$ & 90 & $\ldots$ & $\ldots$ & $\ldots$ & $\ldots$ & 112 \\
\hline Europa & 100 & 98 & 94 & 91 & 94 & 98 & 102 & 105 & 110 \\
\hline Estados Unidos & 100 & 91 & 84 & 74 & 72 & 78 & 84 & 95 & 99 \\
\hline \multicolumn{10}{|l|}{ Producción Industrial } \\
\hline Mundo & 100 & 87 & 75 & 64 & 72 & 78 & 86 & 96 & 103 \\
\hline Europa & 100 & 92 & 81 & 72 & 77 & 86 & 93 & 101 & 110 \\
\hline Norteamérica & 100 & 81 & 68 & 54 & 64 & 67 & 76 & 89 & 93 \\
\hline \multicolumn{10}{|l|}{ Producción de alimentos } \\
\hline Mundo & 100 & 102 & 100 & 100 & 102 & 101 & 101 & 103 & 106 \\
\hline Europa & 100 & 99 & 102 & 104 & 106 & 107 & 107 & 107 & 109 \\
\hline Norteamérica & 100 & 102 & 103 & 100 & 100 & 98 & 91 & 96 & 97 \\
\hline \multicolumn{10}{|l|}{$\begin{array}{l}\text { Producción de materias } \\
\text { primas }\end{array}$} \\
\hline Mundo & 100 & 94 & 85 & 75 & 81 & 87 & 95 & 106 & 119 \\
\hline Europa & 100 & 90 & 82 & 73 & 77 & 85 & 91 & 98 & 109 \\
\hline Norteamérica & 100 & 90 & 80 & 64 & 69 & 71 & 78 & 91 & 108 \\
\hline \multicolumn{10}{|l|}{ Precios mundiales } \\
\hline Alimentos & 100 & 84 & 66 & 50 & 46 & 42 & 40 & 42 & 46 \\
\hline Materias primas & 100 & 82 & 59 & 44 & 40 & 40 & 39 & 41 & 47 \\
\hline Manufacturas & 100 & 94 & 78 & 63 & 56 & 50 & 48 & 48 & 51 \\
\hline \multicolumn{10}{|l|}{ Comercio Mundial } \\
\hline Valor ** & 100 & 80 & 57 & 39 & 35 & 34 & 35 & 38 & 45 \\
\hline Volumen & 100 & 93 & 85 & 74 & 75 & 78 & 82 & 86 & 96 \\
\hline Precios de exportación & 100 & 86 & 67 & 52 & 47 & 44 & 43 & 44 & 47 \\
\hline
\end{tabular}

* En dólares ppc de 1990; ** en dólares oro al tipo de cambio anterior a la devaluación de 1933.

Fuente: El PIB en Maddison (2003), y el resto en Feinstein, Temin y Toniolo (2008: 95 y 164).

El colapso del comercio internacional fue rápido y profundo, agravándose la pérdida de dinamismo heredada de los años 20. La espiral descendente se prolongó hasta 1934 y fue tan acusada que el volumen y valor del comercio mundial no recuperaron el nivel de 1929 ni siquiera en 1937 —en volumen no lo haría sino después de 1950 —. El 
Tabla 1. Producción, precios y comercio mundiales, 1929-1937 (Números índices, 1929=100) comportamiento de los precios, más bajista que el de la producción, fue decisivo para retroalimentar el derrumbe de las cantidades comerciadas, como consecuencia concreta del cambio en la estructura de los precios relativos. La caída de las cotizaciones de los alimentos y materias primas fue más pronunciada que la de las manufacturas. Este deterioro de la relación de intercambio de los productos primarios determinó que los países productores y exportadores de tales bienes limitaran sus importaciones de manufacturas y sustituyeran importaciones, al propio tiempo que suspendían pagos de deuda externa, perjudicando todo ello a los países desarrollados. El resultado final fue la más severa contracción de la demanda que la economía internacional había conocido en mucho tiempo (Feinstein, 2008: 95) y el sesgo autárquico que tomó la economía mundial.

Tabla 2. Tasa de paro en el período de entreguerras (en porcentaje de la fuerza laboral)

\begin{tabular}{|l|r|r|r|r|r|r|c|}
\hline & $1921-29$ & 1930 & 1931 & 1932 & 1933 & 1934 & $1935-38$ \\
\hline Alemania & 4,1 & 9,5 & 13,9 & 17,2 & 14,8 & 8,3 & 3,8 \\
\hline Australia & 5,8 & 13,1 & 17,9 & 19,1 & 17,4 & 15,0 & 9,7 \\
\hline Bélgica & 1,5 & 2,2 & 6,8 & 11,9 & 10,6 & 11,8 & 8,9 \\
\hline Estados Unidos & 4,9 & 8,7 & 15,8 & 23,5 & 24,7 & 21,6 & 17,5 \\
\hline Francia* & 1,2 & & 2,2 & & & & 4,5 \\
\hline Reino Unido & 8,1 & 11,1 & 14,8 & 15,3 & 13,9 & 11,7 & 9,2 \\
\hline Suecia & 3,4 & 3,3 & 4,8 & 6,8 & 7,3 & 6,4 & 5,4 \\
\hline
\end{tabular}

* 1926 en 1921-1929 y 1936 en 1934-1938.

Fuente: Maddison (1991: 174).

La variable macroeconómica con consecuencias sociales más directas, el empleo, experimentó una caída sin precedentes. Por primera vez en la historia el desempleo fue masivo y bastante universal, pues afectó a la mayoría de los países y sobre todo a los más desarrollados, dotados de un importante sector industrial. La tasa de paro alcanzó en ellos cifras de dos dígitos, salvo excepciones, y fue más elevada en los países más industrializados, como Estados Unidos y Alemania, o en los exportadores de productos primarios, como Australia. El desempleo de larga duración significaba para la mayoría de los parados vivir grandes penalidades y estrecheces, sin apenas expectativas de mejora, a causa de la práctica inexistencia del subsidio de paro. El nivel de vida de la población empeoró de forma general, incluidos los agricultores en activo, afectados por el cambio de los precios relativos. Solamente los trabajadores que conservaron el empleo dispusieron de crecientes ingresos reales, dado que la caída de los precios no fue secundada por los salarios, en parte 
gracias a la difusión de los convenios colectivos y, sobre todo, merced a la presión política que ejercieron los gobiernos sobre las empresas y las administraciones públicas para sostener los salarios monetarios ${ }^{2}$. Sin embargo, muchos parados no tenían más remedio que acudir a los centros de asistencia y caridad en busca de lo más esencial para sobrevivir.

Una situación económica de tal magnitud tuvo asimismo su derivación política. Los sectores más extremistas de la opinión pública la imputaban a la inestabilidad intrínseca del capitalismo, erosionando con ello la legitimidad de la economía de mercado, socavando, por extensión, los cimientos de la democracia liberal y justificando iniciativas revolucionarias de tipo fascista o comunista, máxime cuando la URSS sorteaba la crisis internacional y cosechaba los éxitos de una industrialización acelerada.

\section{LOS CAMBIOS ESTRUCTURALES PRECEDENTES Y LA RECONSTRUCCIÓN FALLIDA DE UN MUNDO PERDIDO}

Aunque el origen de la Gran Depresión suele situarse en Estados Unidos, no cabe duda que se trata de un fenómeno global cuyas raíces más profundas se encuentran en los cambios que venían produciéndose desde hacía más de una década. Lionel Robbins (1934:1) escribía en 1933 que «estamos viviendo, no en el año cuarto, sino en el año decimonoveno de la crisis mundial». En la medida que así era debemos preguntarnos por las bases sobre las que se habían asentado los «felices veinte», esa época de rápida expansión y enriquecimiento fácil que parecía revivir los mejores momentos de un mundo que, sin embargo, había desaparecido definitivamente en 1914.

En realidad, las instituciones sobre las que se habían asentado la rápida integración de los mercados internacionales y el crecimiento económico mundial que se vivieron desde finales del siglo XIX hasta 1914 quedaron en suspenso nada más estallar la Gran Guerra. El intento posterior de reconstruirlas no hizo sino crear nuevas fuentes de inestabilidad porque las nuevas condiciones económicas y políticas eran muy diferentes a las de antaño y mucho más inestables ${ }^{3}$. En cierto modo, los cambios estructurales ocurridos

2 Según Bernanke (2000: 87), los salarios nominales en relación con los precios de las manufacturas (product wages) aumentaron a partir de 1929 en Estados Unidos, Reino Unido, Suecia, Alemania y Japón, excepto en 1932-1933 en Alemania y 1936-1938 en Japón.

${ }^{3}$ En opinión de Frieden (2007: 174), «casi todo lo que vino después de 1914 era malo, o acabó mal para casi todo el mundo y todo el tiempo». 
entonces crearon un contexto que hacía más vulnerable la economía ante las crisis facilitando asimismo su difusión internacional (Eichengreen, 1992: 214-221).

El primero de estos cambios se refiere a la composición del producto. En la agricultura, el boom forzado por imperativos de la guerra fue seguido por una fuerte caída de los precios. Después de haber invertido cuantiosos recursos en la compra de tierra y la inversión de maquinaria, los granjeros debían cargar con hipotecas muy gravosas. El peligro de impago suponía un desafío para el sistema financiero, mientras que la presión a favor de crédito barato y protección arancelaria continuó determinando la política de todos los países del mundo a lo largo de la década.

En la industria, los llamados staples trades, característicos de la primera industrialización, como el hierro y el acero, el carbón, los textiles y la construcción naval, cedieron el protagonismo de la expansión a las nuevas industrias, especialmente a la química, la ingeniería eléctrica y la construcción mecánica. Una ola de innovaciones en forma de nuevos materiales, productos y procesos de fabricación en masa, característicos de la llamada Segunda Revolución Industrial, creó literalmente un vasto mercado de bienes de consumo duradero entre los cuales destacaban el automóvil, los electrodomésticos y la radio ${ }^{4}$. Si la radio fue el símbolo de la época, como hoy en día puede serlo Internet, el automóvil se convirtió en el eje central de la economía gracias a la demanda derivada de materiales y a los efectos sobre la construcción de infraestructuras y viviendas. Los avances tecnológicos requerían grandes inversiones en capital fijo, organización y redes de comercialización, cuyo retorno se retrasaba en el tiempo. Aunque las inversiones no estaban exentas de riesgo, los incrementos de productividad que prometían despertaron el entusiasmo de los inversores, que anticipaban así mayores incrementos de beneficios en el futuro. Además, las operaciones a gran escala para un mercado de masas fomentaron la expansión de las grandes fábricas y las concentraciones empresariales tanto como el desarrollo de los mercados financieros, donde empresas y familias podían tomar a crédito el capital que necesitaban para financiar respectivamente la inversión y el consumo. Los años 20 fueron efectivamente una época de innovaciones financieras en las que participaron multitud de nuevos intermediarios que competían por ofrecer nuevas y mayores facilidades crediticias en la colocación de títulos de toda clase, así como en la promoción de las ventas a plazos.

La cuestión que debemos plantearnos al respecto es si estos cambios estructurales tuvieron implicaciones importantes en las fluctuaciones económicas y si agravaron la sensibilidad de la industria a las oscilaciones cíclicas, tanto a la hora de impulsar el auge

${ }^{4}$ En Feinstein, Temin y Toniolo (2007: 74-75) se encuentra una relación de las principales innovaciones de los años inmediatamente anteriores y posteriores a la Primera Guerra Mundial. 
vía crédito como a la de precipitar la caída, cuando el riesgo de perder el empleo y la carga de la deuda retraían las compras de bienes duraderos y los problemas de liquidez de las entidades bancarias obligaban a reducir drásticamente la oferta de crédito.

La expansión de las grandes empresas también trajo consigo importantes cambios en el funcionamiento del mercado laboral que pudieron alterar la capacidad de ajuste de la economía a las fluctuaciones cíclicas. El desempleo industrial fue una característica de la década de 1920, aunque no todos los años ni en todos los países. En Gran Bretaña fue particularmente elevado, también en los países exportadores de productos primarios como Australia, no así en Alemania ni mucho menos en Estados Unidos, Bélgica y Francia, donde se alcanzaron cotas de pleno empleo. La difusión del subsidio de paro no parece haber sido suficiente para contribuir a elevar la tasa de desempleo natural, de hecho una parte muy reducida de la fuerza laboral estaba protegida al respecto. En cambio, las tasas de sindicalización alcanzaron máximos históricos. Aún más importante debió ser la difusión de la negociación colectiva en los tres grandes países industriales. En Alemania era legalmente obligatoria para las grandes empresas desde 1919, en Gran Bretaña implicaba a un tercio o la mitad de la fuerza laboral y en Estados Unidos habían surgido mercados laborales internos en el ámbito de las grandes empresas (Fearon, 1987: 65). En efecto, fueron los ciclos de producción integrados característicos de la gran empresa los que aconsejaron disponer de una mano de obra adiestrada, estable y mejor pagada que en las industrias tradicionales. Ahora bien, en qué medida la sindicalización y la negociación colectiva contribuyeron a reducir la flexibilidad a la baja de los salarios y, por tanto, la capacidad de ajuste a los cambios de ciclo económico es motivo de discusión ${ }^{5}$.

Por último, pero no menos importante, el sistema financiero internacional y los flujos de capital que habían sido fuentes de estabilidad y de integración económica antes de la guerra se convirtieron después en fuentes de inestabilidad y de discordia entre las naciones. La financiación del gasto bélico mediante la creación monetaria había forzado la suspensión del patrón oro en los países beligerantes, excepto en Estados Unidos, que

5 Aparentemente, nada de esto impidió el desfase de los salarios reales respecto a la productividad. Un hecho así pudo influir en la demanda agregada: al concentrarse el ingreso, el gasto dependía de las preferencias de grupos acomodados muy reducidos, que propendían al consumo de bienes duraderos y bienes de lujo y al ahorro y a la inversión en el mercado de valores, pero el comportamiento de estas variables está sometido a mayores fluctuaciones que el gasto corriente de población asalariada. Aunque distribución de la renta empeoró (Fearon, 1985: 67), la proporción del consumo respecto al gasto nacional se mantuvo constante durante la década de 1929 . Según Peter Temin, la tesis del subconsumo no parece plausible (Fearon, 1979: 32). 
oficialmente mantuvo la convertibilidad del dólar. La consiguiente inflación, que en todos los países persistió en la posguerra y en algunos provocó la destrucción de la divisa, hizo recordar la época anterior con nostalgia.

Por tanto, la vuelta al oro fue planteada por la mayoría de los países en la inmediata posguerra como una de las principales tareas de la reconstrucción económica. Sólo de esta manera era posible recuperar, se decía, la confianza en la estabilidad de los tipos de cambio, animar los movimientos de capital y, por consiguiente, afianzar la recuperación de las economías devastadas por la guerra. La conferencia monetaria internacional celebrada en Génova el año 1922 estableció precisamente los principios sobre los que debía asentarse el patrón oro restaurado: convertibilidad, bancos centrales independientes, disciplina fiscal, apoyo condicionado a los países en dificultades y cooperación entre los bancos centrales (James, 2003: 31 y 50-67). Como quiera que el oro escaseaba, las reservas estaban mal repartidas y las balanzas de pagos presentaban importantes desajustes, se hacía necesario economizar el uso monetario del oro. En consecuencia, los países asistentes a la citada conferencia autorizaron, no sin notables discrepancias, que los bancos centrales pudieran completar las reservas de oro con divisas ${ }^{6}$. El patrón oro restaurado era en realidad un patrón cambios oro que se asentaba sobre unas pocas divisas convertibles en oro, entre las cuales debían destacar el dólar americano y la libra esterlina, así como el franco unos años después.

Sin embargo, las consecuencias de la guerra y de los tratados de paz, así como el debilitamiento de Europa en relación con Estados Unidos, no facilitaban el buen funcionamiento del sistema monetario internacional. El problema era que, con los precios mundiales en dólares un $40 \%$ por encima de su equilibrio previo a la guerra, el valor real de las reservas y las provisiones de oro era proporcionalmente menor. Por esta razón el oro escaseaba. Además, las reservas estaban mal repartidas, al permanecer más de la mitad en Estados Unidos ${ }^{7}$. Por último, los problemas de competitividad de las exportaciones europeas, agravados unas veces por la elección de tipos sobrevalorados, otras por los desconfianza respecto a la política fiscal y en el caso de Alemania por el peso de

${ }^{6}$ De hecho, las divisas, que representaban el 12\% de las reservas en 1913 pasaron a ser casi la mitad en 1928 (Eichengreen, 2000: 87-90).

7 Allí se había dirigido el oro, que el recién creado Sistema de la Reserva Federal monetizó, duplicando el valor del dólar y reduciendo a la mitad el valor del oro (Mundell, 2001: 109). Ante esta situación, algunos economistas como Charles Rist, Ludwig von Mises y Gustav Cassel creyeron que la creciente demanda de oro iba a causar una deflación. En realidad, la estabilidad de precios no podía ser mayor que la que ofrecía el valor del oro que servía de base monetaria. 
las reparaciones de guerra, que estaban fijadas en oro, crearon una gran incertidumbre respecto a la estabilidad de los tipos de cambio que agravó la escasez de oro, aumentando la competencia entre los países por adquirir reservas de oro y dificultando ulteriores acuerdos internacionales.

A este respecto, Estados Unidos debía desempeñar un papel fundamental porque había salido de la guerra como el mayor mercado para las exportaciones de los demás países, y la principal fuente de crédito internacional gracias al enorme superávit comercial que había conseguido durante la guerra y a la gran capacidad de ahorro del país. Por desgracia, el proyecto de apertura comercial del Presidente Wilson fue abandonado tan pronto como se aprobó el arancel Fordney-McCumber en 1922, el más alto que había conocido el país hasta entonces, lo cual dificultaba evidentemente las posibilidades de equilibrar las balanzas de pago y sostener los tipos de cambio de los países exportadores. Tampoco la actitud del coloso americano fue constructiva en la cuestión de las deudas interaliadas, lo cual supuso una dificultad añadida en la engorrosa cuestión de las reparaciones de guerra. Por tanto, los flujos de capital americano debían servir para equilibrar las balanzas de pagos de los países europeos, pero también de los productores de bienes primarios. De hecho, el crédito americano permitió a los europeos reconstruir sus economías devastadas por la guerra, Alemania y otros países pudieron corregir enseguida los efectos de la hiperinflación, evitando la recesión, y Gran Bretaña restablecer el patrón oro a la paridad de preguerra, aun cuando el nivel de precios y la balanza de pagos no lo habrían aconsejado. En último término, todas estas situaciones fueron facilitadas por la política monetaria expansiva de Estados Unidos.

Ahora bien, la mayor importancia de las divisas en la composición de las reservas monetarias aumentaba la vulnerabilidad a los choques desestabilizadores. Cualquier reducción de las reservas, o bien a causa de un empeoramiento de la balanza de pagos o bien por un reflujo de capital exterior, podía crear serias dificultades a los países deudores y también a los acreedores, pues, al fin y al cabo, lo más importante eran las reservas de oro que aseguraban la convertibilidad. Sin duda, la ayuda y la cooperación entre los bancos centrales eran imprescindibles para el buen funcionamiento del patrón oro restaurado. Por desgracia, las condiciones políticas y económicas que habían hecho posible el buen funcionamiento del patrón oro antes de 1914 habían desaparecido con la guerra (Eichengreen, 1992a: 9). Uno de los dos pilares del mismo, la credibilidad en el mantenimiento del principio de convertibilidad, estaba siendo erosionado porque ahora los gobiernos tendían a dar mayor prioridad al estímulo de la producción interna y el empleo que al sostenimiento del tipo de cambio. Además, la cooperación internacional, el otro pilar del patrón oro, se veía obstaculizada por las 
restricciones de la política interna y las tendencias proteccionistas, las discrepancias de criterios entre los bancos centrales acerca de la función que debían desempeñar y la cuestión de las deudas y reparaciones de guerra, el asunto más venenoso de las relaciones internacionales de la época.

En resumen, los cambios estructurales reseñados anteriormente pudieron haber facilitado el camino hacia la Gran Depresión. En particular, la fragilidad del patrón oro restaurado agravó el peligro de las fugas de capitales e intensificó la presión sobre los bancos centrales a la hora de escoger entre política de equilibrio interno o externo, mientras que el sistema comercial y financiero global dependía cada vez más del préstamo americano (Eichengreen, 1992b: 221). De hecho, la Gran Depresión fue tan intensa precisamente por ser un fenómeno global del que ninguna economía nacional escapó, de ahí que sea lógico buscar la clave en las instituciones financieras de los distintos países. Desde su origen en Estados Unidos, donde los problemas de la agricultura y los cambios en la industria, los mercados laborales y el consumo habían sido más intensos que en otros países, se difundió al resto del mundo a través de los nervios del sistema monetario internacional que había sido instaurado en la posguerra en medio de tan grandes dificultades. Así, puede entenderse por qué los primeros signos de recesión aparecen en los países deudores.

\section{DE LA CRISIS A LA GRAN DEPRESIÓN}

Las causas de la Gran Depresión fueron muy diversas, cada una por sí sola no parecía especialmente grave, pero una tras otra provocaron unos efectos acumulativos que profundizaron su intensidad y duración. Primero, una leve recesión inducida por el giro de la política monetaria de la Reserva Federal, después el crash de la bolsa de valores y a continuación la crisis financiera, más los problemas de pagos que presentaban los países exportadores de productos primarios y los países deudores, sin olvidar las desafortunadas iniciativas comerciales y fiscales de todos los gobiernos, en fin, todos estos problemas terminaron por convertir una incipiente recesión en una depresión económica tan profunda que arrastró consigo a las instituciones internacionales. De hecho, Los acontecimientos de 1928-1933 no pueden ser entendidos sin vincular el comportamiento de la oferta monetaria con la intervención de la Reserva Federal y la defectuosa estructura del patrón oro del período de entreguerras (Parker: 2007, 4). Sin embargo, la recuperación sólo pudo asentarse en un contexto de evidente fractura de la economía internacional. 


\subsection{El doble giro de la política monetaria en 1927-1928}

El Sistema de la Reserva Federal (Fed) había manejado la política monetaria con aparente maestría y destreza desde su creación en 1913. Los instrumentos de que disponía, las operaciones de mercado abierto y los tipos de descuento, eran utilizados como un auténtico mecanismo de equilibrio con el que regular la oferta monetaria, incrementándola cuando la economía daba muestras de flaqueza y reduciéndola cuando ésta empezaba a crecer demasiado deprisa. Las fluctuaciones económicas no desaparecieron, pero se suavizaron tanto que se anunció la muerte del ciclo económico. Aparentemente, la inflación se mantuvo estable, si bien el rápido incremento de la productividad del trabajo tendría que haberse traducido en un descenso de los precios. De lo que no cabe duda es que una vez superada la recesión posbélica de 1920-1921 se vivieron unos años de intenso crecimiento económico.

La política de la Fed dio un giro expansivo en 1927 por medio de la compra de títulos en mercado abierto y de un recorte de los tipos de interés. Las razones eran en parte de orden interno y en parte de orden externo. En la primavera se había sentido una leve recesión en la producción industrial que se atribuía a la paralización de la Ford para reorganizar la nueva línea de montaje (Kindleberger, 1985: 68, y Eichengreen, 1992a: 213). Además, la caída de los precios agrícolas había afectado gravemente a los granjeros del Medio Oeste. Por otra parte, ahora, siguiendo la política que había permitido a los europeos reconstruir sus economías en la posguerra, era preciso acudir en ayuda de la libra esterlina, cuya posición estaba en peligro debido al empeoramiento de la balanza de pagos británica (Robbins, 1934: 51-53). En efecto, los bajos tipos de interés animaban al capital americano a buscar remuneraciones más altas en el exterior.

Como reconoció el mismo Benjamin Strong, gobernador del Banco de la Reserva Federal de Nueva York, a Charles Rist, vicepresidente del Banco de Francia, esta decisión suponía dar «un pequeño coup de whisky al mercado de valores» (Johnson, 2007: 293). El resultado fue un éxito en la medida que la incipiente recesión se detuvo y que la posición de Londres mejoró. Además, la producción y la bolsa recobraron un nuevo vigor. Asimismo, el volumen de hipotecas rurales y urbanas, y el endeudamiento de empresas y administraciones públicas conocieron una nueva expansión. La política expansiva de la Fed impulsó un rápido aumento de los precios de inmuebles, acciones y activos en general. En fin, que el boom crediticio fue el motor de la expansión de finales de la década puede ser avalado por el hecho de que las reservas de los bancos norteamericanos crecieron más deprisa en la segunda mitad de 1927 que en ningún semestre anterior (Eichengreen y Mitchener: 2004, 203). 
Sin embargo, esta política monetaria acomodaticia no siempre fue vista favorablemente. Aunque apropiada para mantener la estabilidad de precios y evitar los males de la inflación y la deflación (Keynes, 2000 [1923]: 185, Meltzer, 2003: 181), esta política fue criticada por quienes pensaban entonces que había impulsado la inversión en proyectos sin fundamentos reales que pronto resultarían fallidos, sembrando las semillas del crash que llevó a la depresión. Desde la perspectiva de la escuela austriaca, que inspiró la obra de Lionel Robbins (1934), la depresión era inevitable porque la expansión del crédito facilitó el emprendimiento de malas inversiones que tarde o temprano tuvieron que ser liquidadas. En general puede decirse, de acuerdo con esta teoría, que con la expansión crediticia se reduce el tipo de interés respecto al tipo de interés «natural», por lo que los empresarios reciben señales erróneas acerca de las preferencias temporales entre consumo e inversión. Como el auge económico trae consigo un aumento de los precios de los factores de producción, tan pronto como se traslada al conjunto de la economía y el público lo advierte, las inversiones no encuentran salida y los negocios dejan de ser lucrativos, momento en el que comienza la baja (Rothbard, 1972: 12). Las autoridades monetarias pueden prolongar el auge con nuevas inyecciones de liquidez, hasta que finalmente se alarman ante la perspectiva de una inflación incontrolada ${ }^{8}$.

En el seno mismo de la Fed se aprecia un giro al respecto desde principios de 1928 (Meltzer, 2003: 226). De acuerdo con la llamada «doctrina de los saldos reales» (real bills doctrine), que era el principio operativo recogido en la Federal Reserve Act y que aparecía reiteradamente en los informes anuales, la dirección del banco central norteamericano concluyó que una orgía de especulación bursátil estaba desviando recursos de fines productivos y poniendo en peligro la estabilidad de precios y la económica 9 . Como quiera que se consideraba que el valor del dinero estaba determinado por el valor de los activos que los respaldaban, se llegaba a la conclusión de que la supervaloración de los activos bursátiles amenazaba a la economía productiva con la inflación, a la que seguiría necesariamente la deflación.

${ }^{8}$ Una reciente exposición de la teoría del ciclo de Friedrich von Hayek se puede consultar en Feito (2008: 45-72). El resumen de otras teorías que destacan la importancia del boom crediticio en el origen de la depresión, como las de Henry George, John K. Galbraith y Charles P. Kindleberger se pueden encontrar en el sólido estudio, ya citado, de Eichengreen y Mitchener (2004: 187-190), así como en el más reciente apunte de Bordo (2007).

${ }^{9}$ En virtud de esta teoría, a la que también apelaba la Gold Standard Act, toda emisión de dinero debía estar respaldada por bienes reales cuya venta fuera inmediata, de modo que la banca podía crear dinero sobre la base de bienes adicionales. Véase Timberlake (1993: 259-260) y Meltzer (2003: 161). 
Acertada o no en sus fundamentos ${ }^{10}$, el hecho es que la Fed decidió abandonar la política de dinero fácil en enero de 1928. Las operaciones de mercado abierto detuvieron el ritmo de expansión del crédito bancario. La tasa de crecimiento de la oferta monetaria, que había sido del 5,20\% en 1926-27, disminuyó al 3,04\% en 1927-28 y al —-0,91\% en 1928-29 (Eichengreen: 1992b, 223). Por otro lado, la tasa de descuento aumentó desde el 3,5\% hasta el 5\%, el mayor nivel desde la recesión de 1920-1921, aunque en agosto de 1929 llegó al 6\%. Los tipos de interés de los créditos a plazo subieron al 8\% y el interbancario a las cifras inauditas del $15 \%$ y el $20 \%$. No se podía concebir una política más contractiva. La resaca había comenzado.

Enseguida, el aumento de los tipos de interés en Estados Unidos redujo el crédito exterior. El flujo de capital hacia el exterior que había predominado durante los años anteriores cambiaba ahora de dirección en busca de las mayores remuneraciones que ofrecía el mercado americano. Sin embargo, los países deudores que dependían de las importaciones de capital americano sintieron los efectos en el verano de 1928. El cambio de objetivos de la Reserva Federal lejos de reducir la especulación, provocó los primeros efectos recesivos en los Estados Unidos y en los países deudores, cuyos equilibrios de balanza de pagos dependían del préstamo norteamericano. En Alemania, los síntomas de recesión estuvieron asimismo vinculados con la fuga de capitales nativos que huían de los elevados impuestos y de la incesante inseguridad política del país, pero no cabe duda que la retirada de capital americano agravó la situación ${ }^{11}$. Sometidos a la disciplina del patrón oro, los países deudores debían adoptar a su vez restricciones monetarias para sostener sus paridades y atender el servicio de la deuda en la esperanza de reanudar el crédito en el futuro inmediato. Por desgracia, la caída de la bolsa fue seguida por una recesión que agravó el reflujo del crédito americano. Es más, el comercio mundial experimentó una acusada caída que afectó negativamente a las exportaciones americanas. Por tanto, el giro declinante de 1929-1930 no fue sólo el resultado de un giro contractivo de la política monetaria de Estados Unidos, sino un giro restrictivo en la política mundial.

10 Si los títulos estaban sobrevalorados en ese momento aún hoy es motivo de polémica. Véase al respecto la síntesis de Torrero Mañas (2006: 26-27). Según Eichengreen (2000), el auge de la bolsa había aumentado la cantidad de dinero y crédito más espectacularmente que las reservas de oro.

11 James (2000: 81-82). Los capitales americanos sirvieron en parte para resolver los problemas de transferencias provocados por las reparaciones, aunque se cree que llegaron a representar una aportación neta a los recursos alemanes. De hecho, el Reichsbank consideraba que podían ser perniciosos, por lo que trató de recortar el crédito al final de la década (Feinstein, Temin y Toniolo, 2008: 89). 


\subsection{La recesión, agravada por la crisis bursátil y la contracción de las exportaciones}

La bolsa fue el único mercado que mantuvo una tendencia alcista en el verano de 1929, cuando ya eran visibles los primeros síntomas de recesión en la acumulación de existencias y el estancamiento de la producción de bienes duraderos. A pesar de ello, las acciones siguieron subiendo hasta el 19 de septiembre de 1929. A partir de entonces comenzaron a declinar precipitándose abruptamente a la baja en octubre.

Aunque crisis bursátil y depresión no comenzaron a la vez, ni aquella puede ser considerada causa de ésta, no cabe duda que el desastre del mercado de capitales reflejaba las crecientes dificultades económicas. En cierto modo, el estallido de la burbuja especulativa señaló el comienzo de un reajuste retrasado desde hacía tiempo.

Las causas del auge del mercado de valores son todavía objeto de discusión, aunque probablemente se pueden explicar por una mezcla de optimismo, grandes ahorros y crédito fácil (Fearon, 1979: 33). Un incremento de los rendimientos de las acciones como el ocurrido entre 1921 y 1926 — se multiplicaron por cuatro- puede explicar asimismo las expectativas de ganancias ${ }^{12}$. Sin embargo, la intensidad del auge y su continuidad a pesar de las restricciones monetarias que venían imponiéndose desde principios de 1928 hacen pensar que también se buscaban ganancias por medio de plusvalías. Al igual que en episodios similares de épocas anteriores, el auge de la bolsa había sido precedido por unos años de intenso crecimiento económico y ahorro. Es posible que la concentración de la renta como consecuencia del mayor crecimiento de la productividad y los beneficios empresariales respecto a los salarios reales, explique en parte la creciente especulación, si damos por hecho que la propensión marginal a la inversión y al riesgo aumentan con el ingreso. Además, las facilidades crediticias permitían a los pequeños inversores comprar valores on margin, con márgenes relativamente pequeños, aunque en aumento, y ofreciendo como garantía las mismas acciones objeto de compra, acciones que los intermediarios habían adquirido también por medio de créditos, call loans, de los bancos comerciales ${ }^{13}$. Ahora bien, que el riesgo, la imprudencia y la temeridad eran crecientes lo demuestra el continuo frenesí bursátil al mismo tiempo que el tipo de

12 Shiller (2000: 35). Sin duda, los inversores esperaban que las empresas siguieran pagando los altos dividendos característicos de la década de 1920. Véase también Eichengreen (1992: 14).

13 Se generaron también otras innovaciones financieras que desafiaban la transparencia del mercado. Galbraith $(1985,44-45)$ puso de relieve la difusión de una cultura de ganancia fácil y sin 
interés aumentaba durante el verano de 1929. En efecto, ¿por qué arriesgar el ahorro en la Bolsa cuando el crédito tendía a encarecerse y los depósitos bancarios ofrecían un comodísimo y creciente interés? En cualquier caso, los valores bursátiles alcanzaron en el verano de 1929 un punto que no se justificaba por la anticipación razonable de ingresos futuros ${ }^{14}$.

Si la burbuja había ocultado los síntomas de estancamiento durante algún tiempo, ahora las noticias recientes que confirmaban el final de la expansión económica y daban a conocer los resultados nada buenos de algunas empresas, más el descubrimiento de algunos escándalos financieros y el largo debate en el Congreso sobre la reforma arancelaria, anunciaban un cambio en las expectativas de los negocios y una pérdida de confianza por parte de los inversores ${ }^{15}$. El 6 de agosto la Fed subió el tipo de descuento al $6 \%$, pero esta medida pasó desapercibida en la Bolsa. En cambio, el alza de los tipos de interés europeos en septiembre provocó la retirada de los fondos extranjeros invertidos en Estados Unidos y la reducción de los créditos concedidos a los brokers, que ahora debían pagar tipos cercanos al $15 \%$ y aún al 20\%. El auge estaba llegando a su fin. A falta de crédito para continuar las compras, la tendencia de la Bolsa se invirtió y el mismo mecanismo que había impulsado el alza precipitó ahora su hundimiento. El índice que había subido desde 100 en 1926 hasta 200 en septiembre de 1929 cayó a menos de 35 en agosto de 1932 y no recuperó el máximo hasta más de veinticinco años después.

Una vez iniciada, la crisis bursátil tuvo un componente automático, en parte psicológico y en parte financiero. Primero, la compra a crédito con fianza y depósito de acciones significaba que la depreciación de los activos obligaba a los inversores a presentar mayores garantías crediticias. La demanda de liquidez forzaba a solicitar nuevos créditos, a retirar depósitos bancarios o a vender precipitadamente los títulos, arrastrando los malos en su caída a los buenos, cuyos valores, por tanto, continuaron depreciándose. El Banco de la Reserva Federal de Nueva York lanzó varias operaciones de crédito, pero, en realidad, la depreciación de los activos y la retirada de depósitos estaban poniendo en serias dificultades a los bancos, que debieron racionar el crédito, poniendo a su vez en gravísima situación a empresarios, agricultores e industriales, agentes de importación-

esfuerzo en los círculos bursátiles, donde se buscaban grandes plusvalías antes que dividendos, de modo que los valores perdían toda relación con el estado real de las empresas.

${ }^{14}$ La relación precios-beneficios llegó a 32,6 en septiembre, según Shiller (2000: 36). La inversión difícilmente podía ser amortizada con las pequeñas ganancias que proporcionaba el dividendo.

15 Sobre las perspectivas proteccionistas, véase James (2003: 44-45). 
exportación, constructores, propietarios de viviendas y consumidores en general (Kindleberger, 1985: 137).

El crash redujo la demanda agregada de manera sustancial. La caída del consumo por la incertidumbre respecto al ingreso futuro, el empobrecimiento derivado de la pérdida de patrimonio - aunque los valores bursátiles todavía representaban una pequeña parte de la riqueza nacional-, y el racionamiento del crédito por los bancos provocaron una contracción de la demanda, especialmente de bienes de consumo duradero y de bienes de capital. El resultado fue que el producto real, que había disminuido suavemente desde junio, comenzó a precipitarse a finales del 1929 y principios de 1930.

Ciertamente el crash y la recesión comenzaron en fechas diferentes, pero el declive de los valores bursátiles fue un factor que agravó la caída de la producción y el empleo que había comenzado en Estados Unidos unos meses antes y en otros países el año anterior (Romer: 2005). A pesar de todo, el giro de 1929-1930 no parecía exagerado en comparación con otros episodios similares, de ahí el relativo optimismo acerca de las posibilidades de recuperación que aún se percibía en la opinión pública. Como puede apreciarse en la Tabla 2, las tasas de paro habían aumentado un poco en 1930, pero todavía estaban lejos de las cotas de los años posteriores.

Por necesario que fuera, el ajuste automático que podía esperarse en virtud de la Ley de Say no se produjo, en parte por un problema de coordinación, en parte por la llamada del gobierno al sostenimiento de los salarios y del empleo. La rigidez de las rentas monetarias como alquileres, bonos, hipotecas y salarios, difícilmente podía ser corregida sin un mecanismo de coordinación que permitiera a los interesados, rentistas, capitalistas y trabajadores ponerse de acuerdo para hacer mutuas concesiones. La intervención del gobierno reforzó el declive de la demanda en un doble sentido.

Por un parte, la administración Hoover, bajo la influencia de la «nueva economía» de la planificación, y contrariamente a la imagen de laissez-faire que todavía se le atribuye $^{16}$, instó a los empresarios a mantener los salarios y aumentar las inversiones para sostener el poder adquisitivo de los empleados, y a los municipios a emprender obras públicas para sostener el empleo. El resultado fue que el año 1931 se produjo la mayor

16 Johnson (2007: 248 y ss.) recuerda su interés en la planificación. Sobre la importancia que otorgaba al papel del gobierno en la recopilación de información para aumentar la eficiencia de la empresa, el aumento del gasto público en épocas de recesión y los elevados salarios para sostener la demanda, véase Fearon (1987: 50 y 123), quien insiste, por si queda alguna duda, que «Hoover was not a laissez-faire politician». 
expansión fiscal de la década, pero el déficit agravó la desconfianza en las perspectivas de los negocios (Fearon, 1987: 125). Sin embargo, a medida que la demanda disminuía también lo hacían los precios, mientras que los costes fijos de las grandes empresas permanecían constantes, de manera que los beneficios disminuían y, con ellos, la inversión y el empleo.

Para colmo, la Ley Smoot-Hawley aprobada por fin en junio de 1930 elevó los aranceles a cotas sin precedentes, lo que significó una drástica e inmediata reducción del mercado americano para las exportaciones de otros países y una caída de los rendimientos de las inversiones norteamericanos, al igual que las británicas, en el exterior ${ }^{17}$. Evidentemente, los productores americanos ahora no podían sostener sus beneficios desviando las ventas del mercado interior a los mercados exteriores. Al poco tiempo, las represalias no se hicieron esperar y el proteccionismo tomó un rumbo desenfrenado en todo el mundo. Las exportaciones americanas de trigo, maíz, algodón y tabaco, que representaban del $20 \%$ al $55 \%$ de las producciones respectivas, cayeron estrepitosamente, los precios agrarios se hundieron y miles de agricultores fueron a la quiebra. El efecto de la caída de las exportaciones sobre el PIB podía ser cuantitativamente pequeño, pero las consecuencias para la estabilidad del sistema financiero norteamericano y mundial podían ser gravísimas. En Estados Unidos, las hipotecas rurales comenzaban a ser ejecutadas, pero varios estados aprobaron leyes de moratoria que no hicieron sino endosar la quiebra a los acreedores.

\subsection{La espiral deflacionista: de las crisis bancarias al abandono del patrón oro}

A lo largo de 1930 se hicieron visibles los problemas que atravesaba el sistema financiero. La recesión estaba depreciando el valor de las carteras, al tiempo que aumentaba la morosidad de los deudores. Los bancos, cuyas reservas eran una fracción de los depósitos, debieron reclamar la amortización de los créditos con el fin de disponer de liquidez. La presión era naturalmente más acusada sobre los bancos que habían prestado en exceso y con riesgos altos o habían adquirido obligaciones no líquidas a largo plazo, como era el caso de numerosos bancos vinculados con la agricultura, las administraciones locales y el mercado de valores. Fue precisamente en el Medio Oeste

17 «Aceptemos que el arancel Smoot-Hawley, después de tomar en cuenta las represalias, fue una fuerza deflacionaria», dice Kindleberger (1985: 156). 
y el Sur de Estados Unidos donde surgió en noviembre de 1930 la primera oleada de quiebras bancarias que minaron la confianza en los bancos y provocaron numerosos, intentos de convertir los depósitos bancarios en dinero efectivo. El pánico llegó a Nueva York arrastrando al Bank of United States a la quiebra, a pesar de que era una institución solvente (Friedman y Schwartz, 1963: 309-311). En la primavera de 1931 volvió a repetirse un episodio de ámbito en principio regional que se agravó en septiembre y octubre con motivo de la crisis cambiaria europea que había provocado la salida de la libra del patrón oro. Las quiebras volvieron a incrementarse el año siguiente, aunque la última y más grave oleada se produjo en febrero-marzo de 1933. Para entonces, cuatro de cada diez bancos existentes en 1929 habían desaparecido por quiebra, fusión o liquidación, más de 10.000 .

La cantidad de dinero disminuyó en proporciones sin precedentes. Un tercio de los depósitos y el efectivo en manos del público desaparecieron provocando un cambio radical en el carácter de la recesión. El declive de la oferta monetaria profundizó las tendencias deflacionistas deprimiendo el gasto de consumidores y empresarios, o bien porque esperaban mayor deflación o bien por el temor a que el ingreso futuro no permitiera cubrir la emisión de nuevas deudas. Aunque el tipo de interés nominal fue reducido hasta posiciones muy bajas, la misma deflación hacía que los tipos de interés reales fueran insoportables aumentando el peso de la deuda ${ }^{18}$. Por otra parte, y no menos importante, las quiebras bancarias acrecentaron los costes de intermediación, encareciendo el crédito y agravando las condiciones generales de los negocios (Bernanke, 2000: 49).

¿Cómo fue posible un desplome monetario de tales dimensiones? ¿Acaso era inevitable? La estructura descentralizada del sistema bancario norteamericano constituía un elemento de evidente fragilidad ${ }^{19}$, pero la pasividad de la Reserva Federal fue decisiva. A pesar de que las entradas de oro en Estados Unidos aumentaron en los dos primeros años de la depresión, la oferta monetaria siguió descendiendo, cuando, de haberse atenido a las reglas del patrón oro, tendría que haber aumentado conforme lo hacían las

18 Es la tesis de Irving Fisher, que Parker (2004: 16) expone de forma resumida.

19 La Ley McFadden de 1927 corrigió la ley bancaria de 1864 en el sentido de consolidar un sistema descentralizado que prohibía la creación de bancos nacionales que operaran en más de un estado de la Unión. Entre las entidades bancarias de ámbito estatal y las principales plazas financieras del país debían establecerse relaciones puramente mercantiles que no siempre permitían conocer la situación exacta de unas y otras, a diferencia de lo que podían hacer los bancos con sucursales. Asimismo, la política de la Fed de permitir a los bancos operar con una pequeña reserva fraccional, no habiendo entonces fondos de garantía de depósito, contribuyó no poco a la fragilidad de un sistema que acabó siendo presa del pánico. 
reservas. La Fed consideraba suficiente la reducción del tipo de interés, por lo que no intervino a través del mercado abierto para inyectar liquidez a la economía. Si en años anteriores se había preocupado por la estabilidad de precios, ahora daba prioridad a la defensa del tipo de cambio (Mundell, 2001: 111). En la práctica, el oro era esterilizado $^{20}$. La decisión se explica en el contexto de la crisis financiera de 1931 que había estallado en Europa.

Allí las cosas tampoco estaban yendo muy bien. Los sistemas bancarios de todo el continente estaban entrelazados por una red de depósitos extranjeros a corto plazo que en caso de ser repatriados podían provocar graves crisis financieras y cambiarias. Además, los bancos comerciales habían seguido políticas de expansión crediticia que agudizaron la vulnerabilidad ante los cambios de ciclo económico. En particular, la característica banca universal de Austria y Alemania operaba con una elevada proporción de pasivos a corto plazo en manos extranjeras y unos activos a largo plazo de alto riesgo, concentrados e inmovilizados, habría que decir, en empresas y grupos industriales. Las primeras dificultades económicas de ambos países se habían manifestado con motivo de las repatriaciones de capital que siguieron al giro de la política monetaria de la Fed en 1928 y luego conforme aumentaba la demanda de liquidez de la economía norteamericana.

La crisis financiera de 1931 comenzó en Austria en el verano de 1931 con motivo de los rumores acerca de la supuesta insolvencia del Creditanstalt, cuyos activos representaban más de la mitad de la industria del país. Los malos resultados de algunas empresas textiles amenazaban con provocar suspensiones de pagos que podían arrastrar consigo a este y otros bancos de la región. El pánico se propagó inmediatamente a otros países de Europa central, desde Alemania pasó a Gran Bretaña y de este país saltó enseguida a Estados Unidos. El recuerdo de la hiperinflación y sus devastadoras consecuencias, así como el peso de las reparaciones de guerra, movieron a los bancos centrales de Austria y Alemania a imponer políticas monetarias muy restrictivas y a establecer el control de cambios. El consiguiente bloqueo de créditos aumentó la presión sobre las divisas que sostenían el sistema monetario internacional, primero la libra, después el dólar y más tarde el franco. A medida que se erosionaba la confianza, los titulares de depósitos en divisas reclamaban su conversión en oro, que al ser retirado provocaba una pérdida de reservas monetarias.

Si quería proteger las reservas y mantener el tipo de cambio, el Banco de Inglaterra debía elevar los tipos de interés hasta un punto incompatible con el mantenimiento del

${ }^{20}$ En opinión de Meltzer (2003: 282), la pasividad no se explicaría por falta de liderazgo, información sobre los hechos o teorías alternativas para explicarlas, sino por la confianza en un conjunto de ideas inadecuadas acerca de los excesos especulativos y los saldos reales. 
empleo (Eichengreen, 2000: 120). Aunque el sistema financiero inglés era más sólido que el americano y, de hecho, hubo muy pocas crisis, que no quiebras, bancarias durante la Gran Depresión ${ }^{21}$, la balanza por cuenta corriente presentaba un flanco débil a la hora de sostener el tipo de cambio, que en parte había sido posible eludir por medio de la cooperación entre el Banco de Inglaterra y la Fed ${ }^{22}$. A medida que la recesión empeoraba, los rendimientos de las inversiones exteriores disminuían, debilitando aún más la posición de la libra. Así que el 19 de septiembre de 1931 no tuvo más remedio que suspender la convertibilidad y devaluar la libra. Gran Bretaña había abandonado el patrón oro.

El dólar pasó a ser el eslabón débil de la cadena monetaria internacional. Anticipándose a la retirada de las reservas de oro por parte de los titulares extranjeros de depósitos en dólares, que se temía podía desencadenarse tras el abandono de la libra del patrón oro, la Fed decidió elevar los tipos de interés. Para mayor desgracia, la caída de los valores extranjeros generó el colapso del mercado general de los bonos, que golpeó a los bancos americanos en sus carteras de inversión, lo cual no hizo sino agravar la oleada de crisis bancarias. La presión del Congreso animó a emprender grandes operaciones de mercado abierto en el verano y otoño de 1932. Unas reservas de oro del $70 \%$ podían aparentemente justificarlo ${ }^{23}$, aunque el resultado inmediato de estas operaciones fuera una pérdida de reservas ${ }^{24}$. En cualquier caso, cuando empezaban a sentirse los efectos positivos de la intervención, concluyó la legislatura suspendiéndose las sesiones y el sistema canceló su programa de compras.

Además de tardía, esta medida difícilmente podía contrarrestar el efecto depresivo de la ley presupuestaria que el Congreso aprobó y el presidente Hoover sancionó en junio del mismo año 1932. Una ley muy restrictiva que, en aras del equilibrio presupuestario, supuso la mayor subida de la carga impositiva federal en tiempo de paz de la historia

${ }^{21}$ Los grandes bancos por acciones del Reino Unido que operaban sobre todo con activos a corto plazo, letras y efectos comerciales, habían extendido amplias redes de sucursales que permitían eludir los eventuales problemas de liquidez allí donde se presentaran y evitar el pánico bancario. Además, el capital británico seguía estando presente en el exterior y, de hecho, la mayoría de las inversiones exteriores del mundo seguían siendo de origen británico.

${ }^{22}$ Gran Bretaña era también vulnerable debido a su posición en los mercados internacionales de capital, como deudor a corto plazo (James, 2001: 93).

${ }^{23}$ Véanse las declaraciones al respecto de Ogden L. Mills, Secretario del Tesoro, citadas por Friedman y Schwartz (1963: 385).

${ }^{24}$ En palabras de Eichengreen (1992a: 17), ni siquiera los países con mayores reservas de oro, como Estados Unidos y Francia, podían escapar de la restricción impuesta por el patrón oro. 
americana $^{25}$. Con estímulos semejantes difícilmente podía recuperarse el beneficio y la confianza empresarial. A comienzos del año siguiente se desató una nueva oleada de quiebras bancarias, el producto interior bruto siguió cayendo y el paro alcanzó las cotas más elevadas de la Gran Depresión durante el largo período desde la convocatoria de elecciones hasta la toma de posesión del Presidente Roosevelt en marzo de 1933. Una de sus primeras medidas fue suspender la convertibilidad del oro y devaluar el dólar, cuyo precio, a 35 onzas oro, permaneció en vigor hasta 1971.

Recapitulando, si el doble giro de la política monetaria en 1928-1929 fue el impulso que movió la economía hacia la recesión, las crisis financieras de 1930-1931 la amplificaron convirtiéndola en una profunda depresión (Eichengreen, 1992a: 17-18). El sistema de cambios fijos característicos del patrón oro fue el mecanismo de transmisión internacional, más que la causa de la Gran Depresión (Temin, 1995: 50), causa que en todo caso habría que atribuir a las frágiles condiciones en que había sido restaurado en el curso de los años 20. En cualquier caso, las reglas de juego del patrón oro debían asegurar la estabilidad del tipo de cambio al mismo tiempo que imponían un obstáculo insalvable a la acción unilateral incluso a los países con mayores reservas metálicas. Cabía la posibilidad de proceder a una reflación en el marco del patrón oro, pero la espiral proteccionista, las diferentes concepciones acerca del origen de la crisis y el problema de las reparaciones de guerra dificultaban la cooperación internacional hasta hacerla imposible, y Estados Unidos no estaba en disposición de ejercer el papel hegemónico de prestamista en última instancia que la situación exigía (Kindleberger, 1985: 348-349). La única salida parecía estar en un «sálvese quien pueda».

\section{LAS DÉBILES BASES DE LA RECUPERACIÓN ECONÓMICA}

Los contemporáneos que vieron en el boom crediticio de 1928 el origen de la Gran Depresión pensaron que el libre curso de los acontecimientos bastaría para eliminar rápidamente los negocios fallidos y recuperar enseguida la senda del crecimiento económico. En su opinión, la intervención del gobierno no hizo más que empeorar las cosas al retrasar una crisis inevitable. Sin embargo, pocos aceptaban las tesis liquidacionistas, más bien al contrario, a medida que las cosas empeoraban crecía la presión sobre el go-

${ }^{25}$ La carga fiscal de los gobiernos federal, estatales y locales se duplicó aproximadamente durante el período, elevándose del 24,5 del producto neto privado al 28,9\%, según Rothbard (1972: 289). De la misma opinión es Mundell (2001: 111). 
bierno para que tomara iniciativas que aliviaran la miseria de la población desempleada. $\mathrm{Al}$ ir contracorriente, esta posición arrastró consigo el fundamento de la teoría del ciclo económico incluso en el ámbito académico, hasta que los acontecimientos que ahora estamos viviendo parece que de nuevo la han puesto de actualidad (Feito, 2008: 43-97).

Los partidarios de la intervención del gobierno encontrarían poco después en la obra de Keynes el soporte teórico que justificaba el déficit fiscal. Sin embargo, en la época de entreguerras el presupuesto de las administraciones públicas todavía representaba un pequeña proporción del producto interior bruto, de modo que una expansión del gasto tendría efectos muy pequeños sobre la demanda agregada, a menos que aumentara en más del $50 \%$, mientras que, por el contrario, caben pocas dudas de que tendría efectos negativos sobre la confianza en las perspectivas de los negocios (Fearon, 1979: 55).

Los monetaristas han destacado los errores cometidos por las autoridades del Sistema de la Reserva Federal, que había nacido para prevenir las crisis bancarias, pero no supo evitar las sucesivas oleadas de quiebras bancarias ni la consiguiente deflación, a pesar de que el aumento de las reservas de oro podían permitir una expansión de la oferta monetaria. Los instrumentos de que disponía, y que habían sido utilizados en situaciones anteriores, no fueron incompatibles con el patrón oro hasta septiembre de 1931, cuando los flujos del oro giraron saliendo de Estados Unidos ${ }^{26}$.

¿Cuáles fueron entonces las bases de la recuperación económica? La coincidencia entre devaluación y recuperación, con el inevitable retardo de unos meses, es prueba evidente de los efectos positivos del abandono del patrón oro (Eichengreen, 1992b: 232). Las exportaciones de los países que salieron del patrón oro se recuperaron antes y más rápidamente que las de aquellos que permanecieron en él o, sería más exacto decir, a costa de los que permanecieron en él, por cuanto el efecto de la devaluación era similar al del proteccionismo, empobrecer al vecino. No obstante, las ganancias de competitividad de las exportaciones podían ser anuladas a medida que se sucedían las devaluaciones competitivas y se cerraban los mercados de exportación.

Ahora bien, el hecho más importante fue que la devaluación permitió emprender unilateralmente una política monetaria expansiva de la que se beneficiaron en primer lugar los sectores más sensibles al tipo de interés, como la industria de bienes de capital, la construcción, el automóvil y demás bienes de consumo duradero. Asimismo, fue posible poner freno a los pánicos bancarios y estabilizar efectivamente el sistema financiero

${ }^{26}$ Friedman y Schwartz (1963: 396 y 411). Sin embargo, las reservas de oro a finales del año 1932 habían aumentado respecto al mismo período del año anterior, según Eichengreen (1992a: 314). 
(Eichengreen, 1992b: 229 y 233). Gracias a la expansión del crédito, la demanda interior se recuperó elevando los precios, de modo que las exportaciones crecieron muy poco. Por tanto, la recuperación fue dirigida por el mercado interior. En suma, tanto en Gran Bretaña como en Suecia y Estados Unidos la política monetaria hizo la mayor parte del trabajo.

Sin embargo, no todos los países expandieron el crédito con la misma intensidad y, de hecho, las autoridades continuaron siendo cautas respecto al peligro de la inflación. Tanto es así, que la Fed volvió a imponer restricciones monetarias en 1936-1937 por medio del aumento de las reservas obligatorias y del tipo de descuento, así como de ventas de bonos en mercado abierto, medidas que provocaron una recesión y un aumento del paro en 1938.

A diferencia de lo que habitualmente se cree, la intervención gubernamental tuvo efectos, como poco, ambiguos. En Estados Unidos, el sistema financiero fue objeto de regulación ${ }^{27}$ a fin de conseguir transparencia y estabilidad gracias a iniciativas como la Ley Glass-Steagal, que estableció el seguro de depósitos, impuso coeficientes de reserva obligatoria y obligó a separar los bancos de inversión de los bancos de depósito. Por otra parte, el gasto público debía completar la desfallecida demanda privada con proyectos de carreteras, electrificación rural, obras municipales o regadíos. Sin embargo, las diversas iniciativas sobre la regulación de los mercados agrarios, industriales y laborales, algunas de las cuales fueron declaradas inconstitucionales ${ }^{28}$, en particular las políticas de cartelización dificultaron la recuperación económica (Cole y Ohanian, 2004: 779),

27 Se trata probablemente de la más nutrida de su historia, cuya vigencia en muchos aspectos ha perdurado hasta fechas recientes. La Banking Act de 1933, más conocida por Glass-Steagall Act, instauró entre otras cosas el seguro de depósitos bancarios y la separación entre banca comercial y de inversión, lo cual introdujo una profunda reestructuración del sistema bancario americano. La Banking Act de 1935 estableció como organismo regulador permanente la Federal Deposit Insurance Corporation (FDIC), agencia independiente del gobierno con funciones de garantizar los depósitos bancarios y de exigencias al respecto a la banca comercial. En 1933, el Congreso decretó la Securities Act sobre compraventa de valores en mercados primarios y trasparencia informativa sobre acciones y sus emisores, adscribiendo la divulgación del material informativo a la SEC, Securities and Exchange Commision, instituida por la Securities Exchange Act de 1934, la cual se ocupó también de regular los mercados secundarios de capitales y de otorgar a la Fed la capacidad de regular la extensión del crédito a los brokers y las compras on margin.

${ }^{28}$ La National Industrial Recovery Act de 1933, que preveía la organización de cárteles industriales, y la Agricultural Adjustment Administration de 1933, que financiaba a los agricultores por reducir las cosechas, fueron declaradas inconstitucionales en 1936. Mejor suerte tuvieron la 
sembraron la incertidumbre en torno a los derechos de propiedad y erosionaron el beneficio empresarial, lo cual podría explicar el retraimiento de la inversión privada, que verdaderamente no habría recuperado los índices de 1929 hasta la inmediata posguerra (Higgs: 1997, 567). En realidad, el incremento de la demanda agregada atribuible a la política fiscal siguió siendo pequeño hasta el comienzo del rearme, en el Reino Unido a partir de 1936 y en Estados Unidos tres años más tarde.

\section{Conclusiones}

La crisis económica que estamos viviendo actualmente ha traído a la memoria el recuerdo de la Gran Depresión del período de Entreguerras, «la mayor catástrofe económica en tiempos de paz de la historia contemporánea», en palabras recientes de Peter Temin. Los datos macroeconómicos no dejan lugar a dudas sobre su intensidad, difusión y magnitud, ni de sus gravísimas consecuencias sobre el empleo y la estabilidad política de los regímenes parlamentarios, por lo menos en la Europa continental.

Aunque es cierto que su origen se encuentra en Estados Unidos, también lo es que se trata de un fenómeno global cuyas raíces últimas se encuentran en los cambios acaecidos desde la Gran Guerra, los acuerdos de paz y la expansión de los felices 20. El intento de reconstruir las instituciones de 1914, cuando las condiciones económicas y políticas que las hicieron posibles habían desaparecido, no hizo sino abrir una fuente de inestabilidad, que los cambios estructurales de la posguerra agrandaron haciendo a la economía más vulnerable a los cambios de ciclo y facilitando su difusión internacional.

Asimismo, los acontecimientos que surgen a partir de finales de los 20 no pueden comprenderse bien sin vincular la evolución de la oferta monetaria con la política de la Reserva Federal y la defectuosa estructura del patrón oro restaurado. Por esta razón, la recesión que se aprecia primero en 1928 y luego en 1929 no fue sólo el resultado del giro contractivo de la política monetaria de Estados Unidos, sino un giro restrictivo en la política mundial que se difundía a través de los «grilletes de oro», en llamativa expresión de Barry Eichengreen, que eran los tipos de cambio fijos característicos del patrón oro.

Las fuerzas deflacionarias que se habían impuesto desde su restauración fueron ahora agravadas por el crash de la bolsa y la intervención del gobierno, que dificultó el ajuste de los costes a la caída de los precios, y la política proteccionista, que provocó

Work Progress Administration que introdujo el seguro de desempleo, y la Wagner Act, que reconoció los derechos sindicales plenos y la negociación colectiva. 
inmediatamente la difusión de represalias comerciales por todo el mundo. Sin duda, la clave del nuevo curso que tomaron los acontecimientos a partir de 1930 fue la sucesión de quiebras bancarias y crisis cambiarias que culminaron en septiembre de 1931 con la salida de la libra del patrón oro. El empecinamiento de las autoridades monetarias de Estados Unidos, al igual que Francia y otros países del llamado «bloque del oro», en mantener la estabilidad del tipo de cambio fue sin duda fatal, pero es que ni siquiera los países con mayores reservas de oro podían escapar de la restricción impuesta por el patrón oro a la expansión de la oferta monetaria. Una vez más, el recuerdo de los episodios recientes de inflación desbocada, como los que se vivieron en la inmediata posguerra, y el temor a las consecuencias de la pérdida de reservas debió de pesar tanto o más que la evidencia de la deflación que la contracción monetaria estaba provocando en todos los países del mundo.

Por desgracia, Estados Unidos no pudo o no supo asumir el papel hegemónico de prestamista en última instancia que en virtud de su posición en la economía internacional debía haber desempeñado, ni fue posible tampoco llevar a buen término los intentos de cooperación que debían haber conducido a una reflación de la economía mundial. En consecuencia, la recuperación debía asentarse en la expansión de las respectivas economías nacionales, una vez que el abandono del patrón oro y la consiguiente devaluación hicieron posible expandir la oferta monetaria y crediticia, aun a costa de la ruptura de la economía internacional.

\section{REFERENCIAS BIBLIOGRÁFICAS}

Bernanke, Ben (2000), Essays on the Great Depression, Princeton, Princeton University Press. Bordo, Michael D. (2007), «The Crisis of 2007: The Same Old Story, Only the Players Have Changed», en Globalization and Systemic Risk. Chicago, Federal Reserve Bank of Chicago and International Monetary Fund Conference.

Eichengreen, Barry (1992a), Golden Fetters. The Gold Standard and the Great Depression, 1919-1930, Nueva York, Oxford University Press.

- (1992b), «The origins and nature of the Great Slump revisited», Economic History Review, XLV (2), 213-239.

- (2000), La globalización del capital, Barcelona, Antoni Bosch.

- y Mitchener, Kris (2004), «The Great Depression as a Credit Boom Gone Wrong», Research in Economic History (22), 183-237.

Fearon, Peter (1979), The Origins and Nature of the Great Slump, 1929-1939, Londres, MacMillan, 
Fearon, Peter (1987), War, Prosperity and Depression: the U.S. Economy, 1917-45, Lawrence, Kansas, University Press of Kansas.

Feito, José Luis (2008), Causas y remedios de las crisis económicas. El debate económico Hayek-Keynes 70 años después, Madrid, Fundación para el Análisis y los Estudios Sociales.

Feinstein, Charles H.; Temin, Peter y Toniolo, Gianni (2008), The World Economy between the World Wars, Oxford, Oxford University Press.

Frieden, Jeffrey A. (2007), Capitalismo global. El trasfondo económico de la historia del siglo XX, Barcelona, Crítica.

Friedman, Milton y Schwartz, Anna J. (1963), A Monetary History of the United States, 18601960, Washington, Princeton University Press.

Galbraith, John K. (1985), El crac del 29, Barcelona, Ariel.

Higgs, Robert (1997), «Regime Uncertainty. Why the Great Depression Lasted so Long and Why Prosperity Resumed after the War», The Independent Review, 1, (4), 561-590.

JAMES, Harold (2003), El final de la globalización. Lecciones de la Gran Depresión, Madrid, Turner.

Johnson, Paul (2007), Tiempos modernos, Madrid, Homo Legens.

Keynes, John M. (2000), Breve tratado sobre la reforma monetaria, México, Fondo de Cultura Económica.

Kindleberger, Charles P. (1985), La crisis económica, 1929-1939, Barcelona, Crítica.

- (1991), Manías, pánicos y cracs. Historia de las crisis financieras, Barcelona, Ariel.

MadDison, Angus (1991), Historia del desarrollo capitalista, sus fuerzas dinámicas. Una visión comparada a largo plazo, Barcelona, Ariel.

- (2003), The World Economy. Historical Statistics, París, OCDE.

Meltzer, Allan H. (2002), A History of the Federal Reserve. Volume 1: 1913-1951, Chicago, Chicago University Press.

Mundell, Robert A. (2001), «Una revisión del siglo XX», ICE (793), 107-122.

Cole, Harold L. y Ohanian, Lee E. (2004), «New Policies and the Persistence of the Great Depresison. A General Equilibrium Analysis», Journal of Political Economy, vol. 112, núm. 4, págs. 770-816.

PARKer, Randall E. (2007), The Economics of the Great Depression. A Twenty-First Look Back at the Economics of the Interwar Era, Cheltenham, Edward Elgar.

RAppoport, Peter y White, Eugene N. (1994), «Was the Crash of 1929 Expected? », The American Economic Review, 84 (1), 271-281.

Robisns, Lionel (1934), The Great Depression, Newport, Nueva York, Books for Librairies Press.

Romer, Christina (2008), «Great Depression», Encyclopedia Britannica.

Rothbard, Murray N. (1972), America's Great Depression, Auburn, Alabama, Mises Institute, 5. ${ }^{\mathrm{a}}$ ed. 
SHILlER, Robert J. (2000), Exuberancia irracional, Madrid, Turner.

Temin, Peter (1995), Lecciones de la Gran Depresión, Madrid, Alianza Universidad.

Timberlake, Richard H. (1993), Monetary Policy in the United States. An Intellectual and Institutional History, Chicago, University of Chicago Press.

Torrero Mañas, Antonio (2006), Crisis financieras. Enseñanzas de cinco episodios, Madrid, Marcial Pons. 